\title{
Erkek meme kanserli hastaların analizi: tek merkez sonuçları
}

\author{
Analysis of male breast cancer patients: single center results
}

\author{
Sevda Yılmaz, Yeliz Arman Karakaya, Muhammed Raşid Aykota, Utku Özgen, Ergun Erdem
}

Gönderilme tarihi: 22.04.2021

Kabul tarihi: 25.05.2021

\section{Öz}

Amaç: Erkek meme kanseri (EMK) tüm meme kanserlerinin \%1-2'sini oluşturan nadir kanserlerdir. Çalışmamızda kliniğimize başvuran EMK tanılı hastaların klinikopatolojik bulgularını, tedavi yaklaşımımızı ve sonuçlarını incelemeyi amaçladık.

Gereç ve yöntem: Pamukkale Üniversitesi Tıp Fakültesi Genel Cerrahi Kliniği'nde 2006-2020 yılları arasında meme kanseri nedeniyle tedavi edilen 12 erkek hastanın kliniko-patolojik özellikleri, uygulanan tedaviler ve sonuçları retrospektif olarak incelendi.

Bulgular: Hastaların yaş ortalaması 59 yıl (39-82)olup, \%66,7'si 50 yaş üzerindeydi. Ortalama tümör boyutu 27 mm (4-42) olarak saptandı. Hastaların \%58,3 eşlik eden herhangi bir hastalık saptanmadı. Hastaların tamamı kitle şikâyeti ile başvurmuştu ve \%66,7'sinde kitle santral yerleşimliydi. Hastaların \%66,7'sinde tümör sağ meme yerleşimliydi. Hastaların \%91,7'sinde ailede meme kanseri hikâyesi yoktu. Hastaların 2'sinde (\%16,6) meme dışında 2. bir malignite ( 1 hastada mide kanseri, 1 hastada non-Hodgkin lenfoma) mevcuttu. Bir hasta da izlemde kontralateral meme kanseri görüldü. Hastaların \%91,7 modifiye radikal mastektomi (MRM) operasyonu yapıldı. En sık görülen histolijik tip $(\% 83,3)$ invaziv duktal karsinomdu. Hastaların $\% 58,3$ 'ü evre $2 \mathrm{~b}$ ve üzerindeydi. Hastaların \%25'i luminal A, \%50'si luminal B, \%8,3'ü Her 2 + ve \%16,7'si üçlü negatif moleküler alt tipteydi. Hastaların \%83,3'ü adjuvan kemoterapi, \%50'si adjuvan radyoterapi ve \%58,3'ü adjuvan endokrin tedavisi aldı. Hastaların ortalama izlem süresi 68 ay (6-184 ay) ve izlemde 1 hastada lokal nüks, 3 hastada sistemik metastaz ve 1 hastada kontralateral meme kanseri görüldü.

Sonuç: Çalışmamızda nadir bir hastalık olan EMK'nin kliniko-patolojik özellikleri değerlendirilmiştir. Özellikle 50 yaş üstü erkek hastalarda memede kitle mevcudiyetinde EMK konusunda dikkatli olunmalı ve tedavi planlamasında hastalığın genetik temeli gözardı edilmemelidir.

Anahtar kelimeler: Meme kanseri, erkek, erkek meme kanseri.

Yılmaz S, Arman Karakaya Y, Raşid Aykota M, Özgen U, Erdem E. Erkek meme kanserli hastaların analizi: tek merkez sonuçları. Pam Tıp Derg 2021;14:718-725.

\begin{abstract}
Purpose: Male breast cancer (MBC) is a rare cancer that constitute $1-2 \%$ of all breast cancers. We aimed to examine the clinicopathological findings, our treatment approach and results of patients with EMC who applied to our clinic, in our study.

Material and methods: Clinico-pathological features, treatments and results of 12 male patients who were treated for breast cancer were retrospectively analyzed in Pamukkale University Medical Faculty Department of General Surgery between 2006 and 2020.

Results: The average age of the patients was 59 years (39-82), 66.7\% of them were over 50 years old. The mean tumor size was $27 \mathrm{~mm}$ (4-42). No accompanying disease was found in $58.3 \%$ of the patients. All of the patients refered with the complaint of mass and the mass was centrally located in $66.7 \%$ of them. The tumor was located in the right breast in $66.7 \%$ of the patients. There was no family history of breast cancer in $91.7 \%$ of the patients. Two of the patients $(16.6 \%)$ had a second malignancy other than the breast (gastric cancer in 1 patient, non-Hodgkin lymphoma in 1 patient). Contralateral breast cancer was observed in one patient during follow-up. Modified Radical Mastectomy (MRM) operation was performed in $91.7 \%$ of the patients. The most common histoligic type (83.3\%) was invasive ductal carcinoma, $58.3 \%$ of the patients were stage $2 \mathrm{~b}$ and above. Molecular subtyping of the patients was $25 \%$ luminal A, $50 \%$ luminal B, $8.3 \%$ Her $2+$ and $16.7 \%$ triple negative. $83.3 \%$ of the patients were treated with adjuvant chemotherapy, $50 \%$ with adjuvant radiotherapy and $58.3 \%$ with adjuvant endocrine therapy. The mean follow-up period of the patients was 68 months (6-184 months) and 1 patient had local recurrence, 3 patients had systemic metastasis, and 1 patient had contralateral breast cancer.
\end{abstract}

Sevda Yılmaz, Dr. Öğr. Üye. Pamukkale Üniversitesi Tıp Fakültesi, Genel Cerrahi Anabilim, Denizli, Türkiye, e-posta: syilmaz_md@hotmail.com (https://orcid.org/0000-0002-1309-0805) (Sorumlu Yazar)

Yeliz Arman Karakaya, Dr. Öğr. Üye. Pamukkale Üniversitesi Tıp Fakültesi, Patoloji Anabilim, Denizli, Türkiye, e-posta: yelizkarakaya20@gmail. com (https://orcid.org/0000-0002-6669-9972)

Muhammed Raşid Aykota, Dr. Öğr. Üye. Pamukkale Üniversitesi Tıp Fakültesi, Genel Cerrahi Anabilim, Denizli, Türkiye, e-posta: muhammedaykota@hotmail.com (https://orcid.org/0000-0003-1862-6186)

Utku Özgen, Dr. Öğr. Üye. Pamukkale Üniversitesi Tıp Fakültesi, Genel Cerrahi Anabilim, Denizli, Türkiye, e-posta: dr_utkuozgen@yahoo.com (https://orcid.org/0000-0002-6481-1473)

Ergun Erdem, Prof. Dr. Pamukkale Üniversitesi Tıp Fakültesi, Genel Cerrahi Anabilim, Denizli, Türkiye, e-posta: ergunerdem06@gmail.com (https://orcid.org/0000-0001-7697-9305) 
Conclusion: Clinicopathological features of MBC, which is a rare disease, were evaluated in our study. It is important to be careful about MBC in the presence of breast mass, especially in male patients over 50 years of age, and the genetic basis of the disease should not be ignored in treatment planning.

Key words: Breast cancer, male, male breast cancer.

Yılmaz S, Arman Karakaya Y, Rasid Aykota M, Ozgen U, Erdem E. Analysis of male breast cancer patients: single center results. Pam Med J 2021;14:718-725.

\section{Giriş}

Erkek meme kanseri (EMK) tüm meme kanserlerinin \%1-2'sini ve erkeklerde görülen tüm kanser vakalarının \%1'inden azını oluşturan nadir kanserlerdir [1, 2]. Hastalığın nadir olması ve geniş seriye sahip randomize kontrollü çalışmaların eksikliği nedeniyle, erkek meme kanseri ile ilgili bilgilerin kısıtlı sayıdaki tek merkez raporları ve kadın meme kanseri (KMK) çalışmalarından elde edilmesine neden olmuştur. Erkekte meme kanserine kadınlara göre daha ileri yaş ve evrede tanı konulmaktadır [3]. Ayrıca tümörün moleküler subtipi ve genetik mutasyonlarında da farklııklar mevcuttur $[3,4]$. EMK'li hastalarda tedavi şekillerinin değerlendirildiği prospektif randomize çalışmalar mevcut değildir, KMK'leri ile aynı prensiplerle tedavi edilirler [5]. Erkek memesinin yapısı gereği modifiye radikal mastektomi uygulanan standart cerrahi tedavidir, daha önceki retrospektif çalışmalarda radikal mastektomi, modifiye radikal mastektomi ve basit mastektomi arasında lokal rekürrens ve sağkalım açısından fark saptanmamıştır $[6,7]$.

Biz bu çalışmada kliniğimize başvuran EMK tanılı hastaların klinikopatolojik bulgularını, tedavi yaklaşımımızı ve sonuçlarını incelemeyi amaçladık.

\section{Gereç ve yöntem}

Çalışma öncesi, Pamukkale Üniversitesi Tıp Fakültesi Girişimsel Olmayan Klinik Araştırmalar Etik Kurulu'ndan onay alındı. Pamukkale Üniversitesi Tıp Fakültesi Genel Cerrahi Kliniği'nde Ocak 2006-Aralık 2020 yılları arasında meme kanseri nedeniyle tedavi edilen 12 erkek hastanın hastane kayıtları retrospektif olarak incelendi. Hastaların demografik verileri, klinik bulguları, ameliyatşeklive tarihleri, patolojik inceleme sonuçları ve takiplerdeki hasta kayıtları incelendi. TNM evresi, tümöre ait histopatolojik özellikler (tümör tipi, grade, axiller lenf nodu metastazı sayısı, tümör çevresi lenfovasküler invazyon ve periferik sinir invazyonu durumu, tümör çevresi karsinoma insitu varlığı), tümöre ait immunohistokimyasal parametreler (östrojen reseptörü $(E R)$, progesteron reseptörü $(P R)$, Human epidermal growth factor reseptör 2 (HER 2) durumları, Ki 67 progresyon indeksi yüzdesi değerleri), yapılan tedaviler, hastaların lokal nüks ve metastaz durumları not edildi.

Hastaların immünhistokimya sonuçlarından ER ve $P R$ durumları belirlendi ve $\geq \% 1$ değeri pozitif kabul edildi. HER2 durumu, immünohistokimya veya fluoresan in situ hibridizasyon (FISH) sonuçlarından elde edildi. FISH pozitif olan IHC 3+ ve IHC 2+ tümörler HER2 pozitif tümörler olarak sınıflandırıldı; FISH negatif, IHC 1+ veya IHC pozitif olan IHC 2+ tümörler, HER2 negatif tümörler olarak sınıflandırıldı. Son St. Gallen konsensus 2013'e göre moleküler alt tiplendirme yapıldı [8].

Buna göre:

- Luminal A (ER pozitif, PR>\%20, HER2 negatif ve Ki-67 index $<\% 20$ ),

- Luminal B/HER2 negative (ER pozitif, $\mathrm{PR}<\% 20$, HER2 negatif ve Ki-67 index $>\% 20$ ),

- Luminal B/HER2 positive (ER positive, any PR, HER2 positive and any Ki-67 index),

- HER2 pozitif (ER negatif, PR negatif, HER2 pozitif ve herhangi bir Ki-67 index)

- Üçlü negatif (ER negatif, PR negatif, HER2 negatif ve herhangi bir Ki-67 index)

Hastalar yaş, eşlik eden hastalıklar, ailede meme kanseri hikayesi, hastalık evresi, uygulanan tedavi yöntemleri, tümörün histopatolojik özellikleri ve moleküler subtipleri, metastaz ve ortalama takip sürelerine göre değerlendirildi. 


\section{İstatistiksel yöntem}

Tüm istatistiksel analizler, istatistiksel yazılım SPSS (Version 25.0, IBM, Chicago, IL, USA) kullanılarak yapılmıştır. Hastalara ait temel özellikler, \%95 güven aralığında ortalama \pm standart sapma olarak belirtilmiştir. Hastalıksız sağkalım, tanıdan nüks/progresyon tarihi veya ölüm tarihine kadar geçen süre, genel sağkalım ise tanı tarihi ile son muayene tarihi veya herhangi bir sebeple ölüm tarihi arasındaki süre olarak tanımlandı. Sağ kalımların belirlenmesinde Kaplan- Meier yöntemi kullanılmıştır.

\section{Bulgular}

Çalışmaya 2006-2020 yılları arasında meme kanseri tanısı ile tedavi edilen 12 erkek hasta dahil edildi. Erkek hastalar, aynı dönemde kliniğimizde takip ve tedavi edilen toplam 716 meme kanseri tanılı hastanın \%1,67'sini oluşturmaktaydı. Hastaların yaş ortalaması $59,16 \pm 14,17$ (39-82), tanı anında tümör boyutu ortalaması $28,41 \pm 10,77 \mathrm{~mm}$ (4-42) olarak saptandı. Hastaların 7'sinde $(\% 58,3)$ eşlik eden bir hastalık saptanmazken, 2'sinde $(\% 16,7)$ hipertansiyon (HT), 1'inde $(\% 8,3)$ diyabetes mellitus (DM), 1'inde $(\% 8,3)$ kronik obstrüktif akciğer hastalığı (KOAH) ve 1 'inde $(\% 8,3) \mathrm{HT}$ ve DM birlikte saptandı.

Hastaların tamamı kitle şikayeti ile başvurmuştu. Kitle 8 hastada $(\% 66,7)$ sağ memede ve yine 8 hastada $(\% 66,7)$ santral yerleşimliydi. Hastaların \%91,7'sinde ailede meme veya hormon ilişkili herhangi bir kanseri hikayesi yoktu. İki hastada meme dışında ikinci kanser saptandı (1 mide kanseri, 1 nonHodgkin lenfoma). Bir hasta da $(\% 8,3)$ izlemde kontralateral meme kanseri saptanmıştır.

Hastaların 4'ü (\%33,3) evre 2a, 3'ü (\%25) evre $2 b$, 2'si $(\% 16,6)$ evre $3 c$ ve 1 tanesi $(\% 8,3)$ evre 4 idi. Hastaların 11 'ine $(\% 91,7)$ modifiye radikal mastektomi (MRM), 1'ine $(\% 8,3)$ mastektomi ve sentinel lenf nodu biyopsisi (SLNB) operasyonu yapıldı, MRM yapılan hastalardan birinde izlemde kontralateral meme kanseri gelişmesi nedeni ile kontralateral mastektomi ve SLNB operasyonu gerçekleştirildi.
Hastaların ortalama izlem süresi 68 ay (6184 ay) olup ayrıntılı klinikopatolojik özellikleri Tablo 1'de verilmiştir. Takiplerde kaybedilen (ex) 4 hastanın özellikleri Tablo 2'de verilmiştir. $\mathrm{Bu}$ hastalardan biri mide taşlı yüzük hücreli karsinom nedeni ile 2 hasta kemoterapiye bağlı nedenlerle, bir hastada akciğer metastazına bağlı solunumsal nedenlerle kaybedilmiştir. Kemoterapiye bağı akut böbrek yetmezliği sonucu 1.ayda kaybettiğimiz hasta ortalama izlem süresine dahil edilmemiştir.

Olguların genel sağ kalım süresi $118,15 \pm 39,44$ ay, hastalıksız sağ kalım süresi $74,5 \pm 2,5$ aydır. Şekil 1 'de hastalık evresine göre genel sağ kalım süreleri verilmiştir. 1 hastada $(\% 8,3)$ lokal nüks, 1 hastada $(\% 8,3)$ metastaz gelişmiştir.

\section{Tartışma}

Meme kanseri, kadınlarda en sık görülen kanser olmasına karşın erkeklerde son derece nadirdir ve tüm meme kanseri vakalarının \%12'sini oluşturur. Insidans ırk ve bölgeye göre bazı değişiklikler gösterebilir. Örneğin Avrupa ve Amerika'da \%1 iken Japonya'da \%0,5, Uganda ve Zambia gibi Afrika ülkelerinde ise \%5-15 oranında bildirilmektedir [9, 10]. Ülkemizde EMK oranı tüm meme kanserlerinin \%1-1,7'sini oluşturmaktadır [11]. Serimizde EMK oranı tüm meme kanserlerinin \%1,67'sidir.

Etyolojide birçok risk faktörü tanımlanmıştır ve bunların çoğu östrojen fazlalığı ile ilgilidir. Son yıllarda birçok merkezde gen analizlerinin yapılmaya başlanması, kanserin gen mutasyonlarıyla ilişkisini de ortaya koymuştur. Tüm meme kanserlerigözönüne alındığında \%510 oranında gen mutasyonları saptanmaktadır. Erkek meme kanserlerinde de bu mutasyonlar saptanabilir ve saptanan bu mutasyon çoğu kez BRCA 2 ile ilişkilidir [12]. EMK'li hastalarda yüksek BRCA 1-2 mutasyon oranlarına rağmen sadece üçte bir oranında genetik test yapıldığı bildirilmektedir [13, 14]. Bazı hastalarda genetik mutasyon saptanmamasına rağmen kuvvetli aile hikayesi olabilmektedir. Nitekim serimizde bir hastada aile anamnezi mevcuttur. 
Tablo 1. Hastaların klinikopatolojik özellikleri

\begin{tabular}{|c|c|c|}
\hline & & n (\%) \\
\hline \multirow{2}{*}{ Yaş } & $<50$ & $4(33,7)$ \\
\hline & $\geq 50$ & $8(66,7)$ \\
\hline \multirow{2}{*}{ Tümör Çapı (cm) } & $\leq 2$ & $3(25)$ \\
\hline & $>2$ & $9(75)$ \\
\hline \multirow{4}{*}{ Nodal Durum } & No & $3(25)$ \\
\hline & $\mathrm{N} 1$ & $5(41,7)$ \\
\hline & N2 & $1(8,3)$ \\
\hline & N3 & $3(25)$ \\
\hline \multirow{4}{*}{ Evre } & 1 & 0 \\
\hline & 2 & $9(75)$ \\
\hline & 3 & $2(16,7)$ \\
\hline & 4 & $1(8,3)$ \\
\hline \multirow{3}{*}{ Grade } & 1 & 0 \\
\hline & 2 & $7(58,3)$ \\
\hline & 3 & $5(41,7)$ \\
\hline \multirow{2}{*}{ ER } & Pozitif & $9(75)$ \\
\hline & Negatif & $3(25)$ \\
\hline \multirow{2}{*}{ PR } & Pozitif & $8(66,7)$ \\
\hline & Negatif & $4(33,3)$ \\
\hline \multirow{2}{*}{ HER 2} & Pozitif & $4(33,4)$ \\
\hline & Negatif & $8(66,7)$ \\
\hline \multirow{3}{*}{ Histolojik Tip } & İnvaziv Duktal Karsinom & $10(83,3)$ \\
\hline & İntrakistik Papiller Neoplazi & $1(8,3)$ \\
\hline & $\begin{array}{l}\text { Nöroendokrin Diferansiasyon } \\
\text { Gösteren İnvaziv Karsinom }\end{array}$ & $1(8,3)$ \\
\hline \multirow{4}{*}{ Moleküler Alt tip } & Luminal A & $3(25)$ \\
\hline & Luminal B & $6(50)$ \\
\hline & HER2 pozitif & $1(8,3)$ \\
\hline & Üçlü negatif & $2(6,7)$ \\
\hline \multirow{2}{*}{ Ameliyat Tipi } & MRM & $11(91,7)$ \\
\hline & Mastektomi +SLNB & $1(8,3)$ \\
\hline Adjuvan Kemoterapi & Evet & $10(83,3)$ \\
\hline Adjuvan Radyoterapi & Evet & $6(50)$ \\
\hline Adjuvan Endokrin Tedavi & Evet & $7(58,3)$ \\
\hline \multirow{2}{*}{ Lokal Nüks } & Var & $1(8,3)$ \\
\hline & Yok & $11(91,7)$ \\
\hline \multirow{2}{*}{ Metastaz } & Var & $1(8,3)$ \\
\hline & Yok & $11(91,7)$ \\
\hline \multirow{3}{*}{ Mortalite } & Yaşıyor & $8(66,7)$ \\
\hline & Kansere bağlı ölüm & $4(33,3)$ \\
\hline & Kanser dışı ölüm & 0 \\
\hline
\end{tabular}

ER: Östrojen reseptörü, PR: progesteron reseptörü, HER 2: Human epidermal growth factor reseptör 2, MRM: Modifiye radikal mastektomi, SLNB: Sentinel lenf nodu biyopsisi 







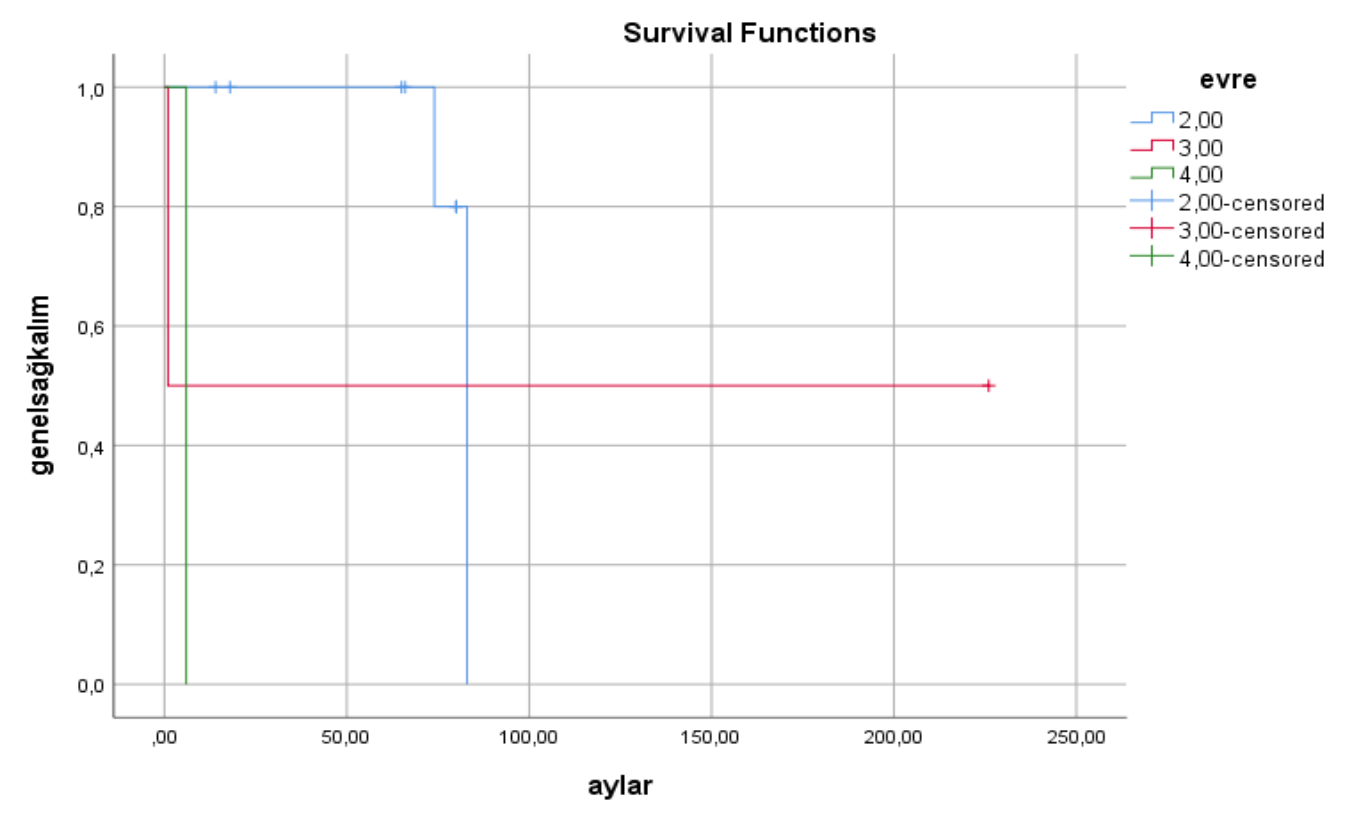

Şekil 1. Erkek meme kanserli hastalarda hastalık evresine göre sağkalım eğrileri

EMK kadınlara göre daha ileri yaşlarda görülmektedir, ortalama tanı yaşı 67 olarak bildirilmektedir [2]. Ülkemizden bildirilen çeşitli serilerde yaş ortalaması 59-63 yaş arasındadır $[11,15,16]$. Çalışmamızda yaş ortalaması Türkiye verilerine uygun olarak 59 olarak saptanmıştır.

EMK çoğunlukla santral yerleşimli, ağrısız, sert bir kitle ile ortaya çıkmaktadır, kadınlarda olduğu gibi bir meme dokusu olmadığı için kısa sürede meme başında çekinti, ülserasyon ve akıntı gibi değişikliklere yol açmaktadır [4, $15,17]$. Serimizde hastaların tamamında kitle şikayeti mevcuttu ve yarısından fazlasında bu kitle santral yerleşimliydi. Gecikmiş olgularımızın hepsinde meme başı değişikliği mevcuttu.

Hemminki ve ark.'nın [13] 3409 erkek meme kanserli hastayı incelendiği geniş volümlü serilerinde hastaların \%12,5'unda ikinci bir neoplazi geliştiği bildirilmektedir. Literatürde diğer bazı serilerde \%17 ve \%33 olmak üzere sekoder neoplazi oranları bildirilmektedir $[14,18]$. Serimizde de $\% 16,7$ oranında ikincil malignite saptanmış olup, bu hastalar sekonder maligniteye bağlı sorunlar nedeniyle kaybedilmişti.

Normal erkek memesinde klasik lobül yapısı gelişmediği için biyolojik olarak EMK'leri kadın meme kanserlerinden farklı özelliklere sahiptir.
EMK'lerinde en sık görülen histopatolojik tip invaziv duktal karsinomdur, yapılan çalışmalarda invaziv duktal karsinom \%64-93,4 oranında bildirilirken invaziv lobüler karsinom \%1,5 oranında bildirilmektedir [19, 20]. Kadınlarda ise invaziv lobüler karsinom tüm meme kanserlerinin $\% 12$ ile 2 . en sık histopatolojik tipini oluşturmaktadır [19]. Serimizde olguların çoğu invaziv duktal karsinom veya onun alt tipidir ve invaziv lobüler karsinom görülmemiştir.

Histolojik grade KMK'leri için prognostik bir faktördür ve yüksek grade kötü sağ kalımla ilişkilidir. EMK'erinde bazı serilerde yüksek grade ağırıklı olarak bildirilmekte [21], diğer bazı serilerde ise düşük ve orta gradein çoğunlukta olduğu bildirilmektedir [16, 22]. Çalışmalarda EMK'leri için grade ve prognoz arasında biri ilişki saptanmamıştır [11, 23]. Serimizde orta grade ağırlıklı olmak üzere orta ve yüksek grade tümörler saptanmış olup düşük gradeli tümör saptanmamıştır.

EMK'lerinde tümörün moleküler alt tiplerinin değerlendirildiği geniş bir seride $\% 81,5$ oranında hormon reseptör pozitif tümör, $\% 14,9$ oranında HER 2 pozitif tümör ve \%3,6 oranında üçlü negatif tümör saptanmıştır [24]. Başka çalışmalarda ER'de \%64-90, PR'de \%70-81 oranında pozitiflik bildirilmiştir [19, 25]. Serimizde vakaların büyük çoğunluğunu hormon reseptör pozitif tümörler oluşturmaktadır. Serimizde 
HER 2 pozitif tümör moleküler alt tipi görülme oranı $\% 8,3$, üçlü negatif tümör görülme oranı $\% 16,7^{\prime}$ 'dir.

EMK erkeklerdeki meme yapısı nedeniyle çoğu kez ileri evrede saptanır, ancak tanı sırasında metastatik hastalık oranı SEER verileri de dahil olmak üzere \%10'un altındadır [10, $19,26]$. Serimizde de hastaların \%58,3'ü evre $2 \mathrm{~b}$ ve üzerindeydi ve tanı sırasında metastatik hastalık oranı \%8,3 idi.

Meme kanserinde günümüzde en önemli prognostik faktör aksiller lenf nodu tutulumudur. Değişik çalışmalarda aksiller nodal metastaz oranı \%41-66 arasında bildirilmektedir [11, 15, 27, 28]. Çalışmamızda aksiller nodal tutulum oranı metastaz $\% 75$ olarak bulundu.

EMKtedaviprensipleriKMKileaynı prensipleri içerir, cerrahi tedavi esastır. Literatürde önceki serilerde MRM ile lumpektomi ve aksiller diseksiyonun karşılaştırıldığı çalışmalarda anlamlı farklılık saptanmamıştır [29, 30]. Çalışmamızda hastalarımızın tamamına aksiller diseksiyonla birlikte mastektomi uygulanmıştır. Sadece bir hastada aksiller diseksiyon yerine SLNB yapılmıştır.

Adjuvan sistemik tedaviler, KMK hastalarında sağ kalım yararı gösterilmiş bir tedavi yöntemidir, ancak EMK hastalarında adjuvan tedaviler ile ilgili görüşbirliği yoktur [31, 32]. Genel olarak EMK'de geniş seriler olmadığından KMK deneyiminden yararlanılarak benzer tedaviler uygulanmaktadır. Nitekim serimizde adjuvan tedavilerde KMK hastalarına benzer protokol uygulanmıştır.

Çalışmamızın limitasyonları retrospektif bir çalışma olması ve kısıtlı hasta sayısı içermesidir. Bu nedenle sağkalıma etki eden faktörler değerlendirilememiştir.

Sonuç olarak, EMK birçok yönden kadın meme kanseriyle benzerlik gösterse de farklı bir takım özellikler taşıdığı açıktır. Geniş hasta gruplarını içeren prospektif çalışmalar olmadıkça, EMK'da elde ettiğimiz sonuçların KMK'de elde ettiğimiz sonuçlara benzer olması nedeniyle, halen uygulanmakta olan tedavileri ideal tedavi olarak kabul etmek durumundayız.

Çıkar ilişkisi: Yazarlar çıkar çatışması olmadığını bildirmişlerdir.

\section{Kaynaklar}

1. Surveillance Epidemiology and End Results (SEER) Incidence Data. SEER Available at: www.seer.cancer. gov. Accessed April 22, 2021

2. Jemal A, Siegel R, Ward E, Hao Y, Xu J, Thun MJ. Cancer statistics, 2009. CA: Cancer J Clin 2009;59:225249. https://doi.org/10.3322/caac.20006

3. Anderson WF, Jatoi I, Tse J, Rosenberg PS. Male breast cancer: a population-based comparison with female breast cancer. J Clin Oncol 2010;28:232-239. https://doi.org/10.1200/JCO.2009.23.8162

4. Temellï Ö, EkiCì C, Ekïii K. Erkeklerde meme kanseri ve tedavi özellikleri. 2015;26:42-46. https://doi. org/10.5505/jkartaltr.2015.92653

5. SEER Cancer Statistics Review, 1975-2017. SEER Available at: https://seer.cancer.gov/csr/1975_2017/ index.html. Accessed November 2019

6. Rushton M, Kwong A, Visram H, Graham N, Petrcich W, Dent S. Treatment outcomes for male breast cancer: a single-centre retrospective case-control study. Curr Oncol 2014;21:400-407. https://doi.org/10.3747/ co.21.1730.

7. Zaenger D, Rabatic BM, Dasher B, Mourad WF. Is breast conserving therapy a safe modality for early-stage male breast cancer? Clin Breast Cancer 2016;16:101104. https://doi.org/10.1016/j.clbc.2015.11.005

8. Cardoso F, Kyriakides S, Ohno S, et al. Early breast cancer: ESMO Clinical Practice Guidelines for diagnosis, treatment and follow-up†. Ann Oncol 2019;30:1194-1220. https://doi.org/10.1093/annonc/ $\mathrm{mdz} 173$

9. Leon Ferre RA, Giridhar KV, Hieken TJ, et al. A contemporary review of male breast cancer: current evidence and unanswered questions. Cancer Metastasis Rev 2018;37:599-614. https://doi. org/10.1007/s10555-018-9761-x

10. Fentiman IS, Fourquet A, Hortobagyi GN. Male breast cancer. Lancet 2006;367:595-604. https://doi. org/10.1016/S0140-6736(06)68226-3

11. Oruc Z. Erkeklerde Meme kanseri ve klinik özellikleri: tek merkez deneyimi. Dicle Tıp Derg 2020;47:920-928. https://doi.org/10.5798/dicletip.850502

12. Thorlacius $\mathrm{S}$, Sigurdsson $\mathrm{S}, \mathrm{Bjarnadottir} \mathrm{H}$, et al. Study of a single BRCA2 mutation with high carrier frequency in a small population. Am J Hum Genet 1997;60:10791084

13. Hemminki K, Scélo G, Boffetta P, et al. Second primary malignancies in patients with male breast cancer. $\mathrm{Br}$ J Cancer 2005;92:1288-1292. https://doi.org/10.1038/ sj.bjc. 6602505

14. Wan BA, Ganesh V, Zhang L, et al. Treatment outcomes in male breast cancer: a retrospective analysis of 161 patients. Clin Oncol 2018;30:354-365. https://doi. org/10.1016/j.clon.2018.02.026 
15. Seviinç $A \dot{I}$, Canda $A E$, Atila $K$, et al. Erkeklerde meme kanseri: 22 olgu. Meme Sağlığı Derg 2007;3:14-18.

16. Selcukbiricik F, Tural $D$, Aydoğan F, Beşe N, Büyükünal E, Serdengeçti $S$. Male breast cancer: 37-year data study at a single experience center in turkey. J Breast Cancer 2013;16:60-65. https://doi.org/10.4048/ jbc.2013.16.1.60

17. Park S, Kim JH, Koo J, Park BW, Lee KS. Clinicopathological characteristics of male breast cancer. Yonsei Med J 2008;49:978-986. https://doi. org/10.3349/ymj.2008.49.6.978

18. Masci G, Caruso M, Caruso F, et al. Clinicopathological and Immunohistochemical Characteristics in Male Breast Cancer: a retrospective case series. Oncologist 2015;20:586-592. https://doi.org/10.1634/ theoncologist.2014-0243

19. Giordano SH, Cohen DS, Buzdar AU, Perkins G, Hortobagyi GN. Breast carcinoma in men: a populationbased study. Cancer 2004;101:51-57. https://doi. org/10.1002/cncr.20312

20. Gennari R, Curigliano G, Jereczek Fossa BA, Male breast cancer: a special therapeutic problem. Anything new? (Review). Int J Oncol 2004;24:663-670.

21. Heinig J, Jackisch C, Rody A, Koch O, Buechter D, Schneider HPG. Clinical management of breast cancer in males: a report of four cases. Eur J Obstet Gynecol Reprod Biol 2002;102:67-73.

22. Morimoto T, Komaki K, Yamakawa T, et al. Cancer of the male breast. J Surg Oncol 1990;44:180-184. https://doi.org/10.1002/jso.2930440311

23. Borgen PI, Wong GY, Vlamis V, et al. Current management of male breast cancer. A review of 104 cases. Ann Surg 1992;215:451-457. https://doi. org/10.1097/00000658-199205000-00007

24. Chavez Macgregor M, Clarke CA, Lichtensztajn D, Hortobagyi GN, Giordano SH. Male breast cancer according to tumor subtype and race: a populationbased study. Cancer 2013;119:1611-1617. https://doi. org/10.1002/cncr.27905

25. Olsson $\mathrm{H}$. Estrogen receptor content in malignant breast tumors in men--a review. J Mammary Gland Biol Neoplasia 2000;5:283-287. https://doi. org/10.1023/a:1009546811429

26. Nahleh ZA, Srikantiah $R$, Safa $M$, Jazieh AR, Muhleman A, Komrokji R. Male breast cancer in the veterans affairs population: a comparative analysis. Cancer 2007;109:1471-1477. https://doi.org/10.1002/ cncr.22589

27. Crichlow RW, Galt SW. Male breast cancer. Surg Clin North Am 1990;70:1165-11677. https://doi.org/10.1016/ S0039-6109(16)45237-0
28. Vermeulen MA, Slaets L, Cardoso F, et al. Pathological characterisation of male breast cancer: results of the EORTC 10085/TBCRC/BIG/NABCG International Male Breast Cancer Program. Eur J Cancer 2017;82:219227. https://doi.org/10.1016/j.ejca.2017.01.034

29. Margaria E, Chiusa L, Ferrari L, Dal Canton O, Pich A. Therapy and survival in male breast carcinoma: a retrospective analysis of 50 cases. Oncol Rep 2000;7:1035-1039.

30. Evans GF, Anthony T, Turnage RH, et al. The diagnostic accuracy of mammography in the evaluation of male breast disease. Am J Surg 2001;181:96-100. https:// doi.org/10.1016/s0002-9610(00)00571-7

31. Hong $\mathrm{JH}, \mathrm{Ha} \mathrm{KS}$, Jung $\mathrm{YH}$, et al. Clinical features of male breast cancer: experiences from seven institutions over 20 years. Cancer Res Treat 2016;48:1389-1398. https://doi.org/10.4143/crt.2015.410

32. Darkeh MHSE, Azavedo E. Male breast cancer clinical features, risk factors, and current diagnostic and therapeutic approaches. Int J Clin Med 2014;5:10681086. https://doi.org/10.4236/ijcm.2014.517138

Etik kurul onayı: Pamukkale Üniversitesi Tıp Fakültesi Girişimsel Olmayan Klinik Araştırmalar Etik Kurulu'ndan 26.11.2020 tarih ve 23 sayılı kurul kararıyla onay alınmıştır.

\section{Yazarların makaleye olan katkıları}

S.Y. ve E.E. çalışmanın ana fikrini ve hipotezini kurgulamışlardır. S.Y., E.E. ve Y.A.K. teoriyi geliştirmiş, gereç ve yöntem bölümünü düzenlemişlerdir. Sonuçlar kısmınındaki verilerin değerlendirmesini M.R.A. ve U.Ö. yapmışlardır. Makalenin tartışma bölümü S.Y. ve E.E. tarafından yazıımış, E.E. gözden geçirip gerekli düzeltmeleri yapmış ve onaylamıştır. Ayrıca tüm yazarlar çalışmanın tamamını tartışmış ve son halini onaylamıştır. 